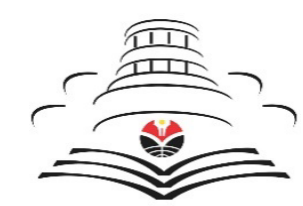

JURNAL UPI

\title{
Visual analysis of self-presentation of teenagers and emerging adults on Facebook
}

\author{
Nor Fariza Mohd Nor ${ }^{1 *}$ and Nur Hazirah Binti Mohd Fuat ${ }^{2}$ \\ ${ }^{1}$ Center for Research in Language and Linguistics, Faculty of Social Sciences and Humanities, Universiti \\ Kebangsaan Malaysia, Bangi, Selangor, Malaysia \\ ${ }^{2}$ Sekolah Jenis Kebangsaan Cina, Petaling Jaya, Kuala Lumpur, Malaysia
}

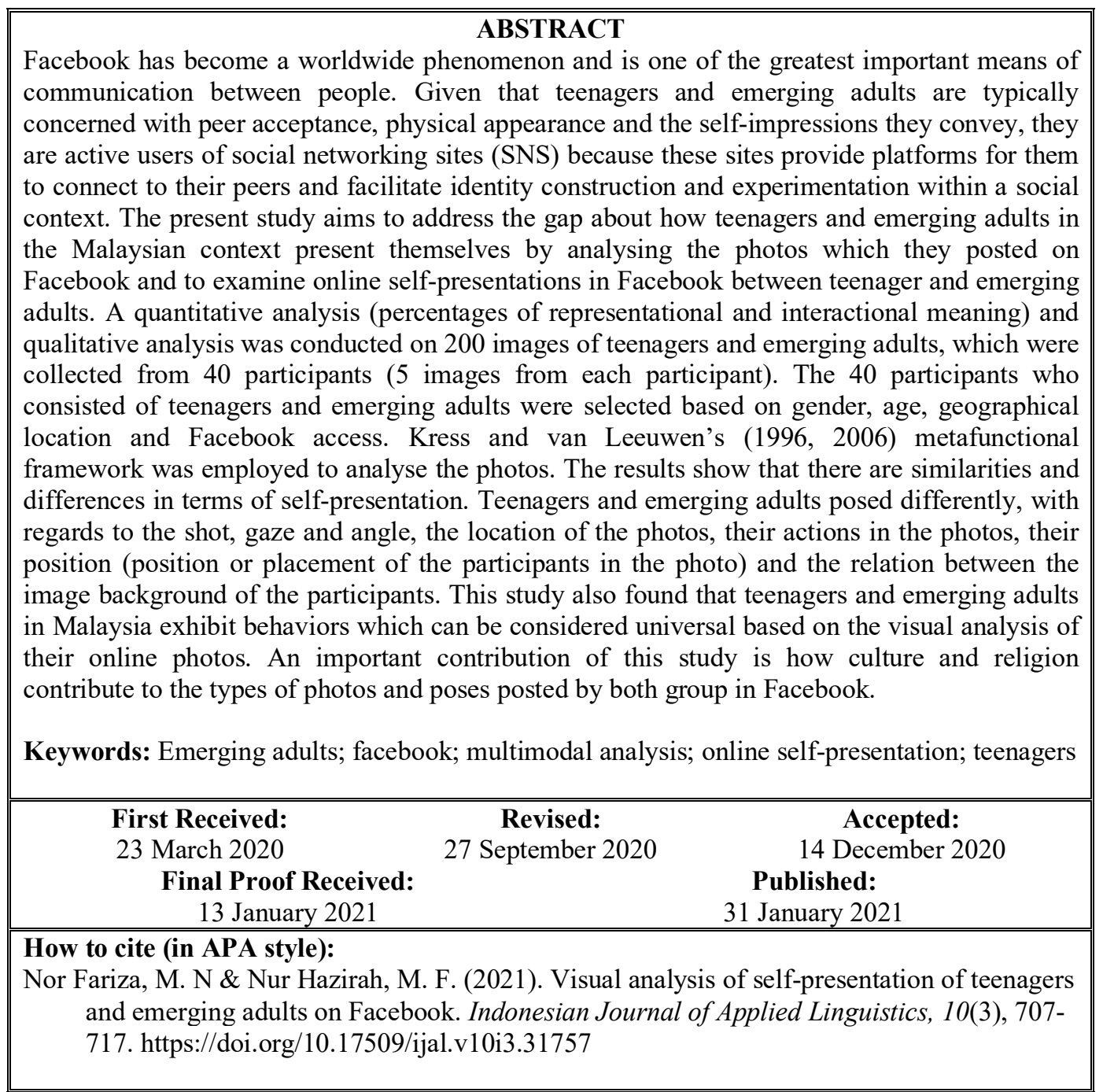

\section{INTRODUCTION}

Social media has experienced emerging widespread popularity, particularly so for social networking sites (henceforth, SNS), especially Facebook because SNS has impeccably combined email, instant messaging, website creation, blogging and multimedia content sharing (Livingstone, 2008).
Facebook has become a worldwide phenomenon and is one of the greatest important means of communication between people. As of January 2020, Facebook is the most popular social networks, ranked by the number of active users, with 2.45 billion users. Facebook users are women between the ages of 18 and 24 years, comprising of teenagers

\footnotetext{
*Corresponding Author

Email: fariza@ukm.edu.my
} 
and emerging adults. Emerging adults are defined as those who are going through a developmental period from the late teens through early twenties. Reports have surfaced that teenagers spend a considerable portion of their daily life interacting through social media (Neira \& Barber, 2014; Yang \& Brown 2016).

Prensky (2001, p. 2) refers to this group of SNS users as "digital natives" who were born and raised in the age of computers and online communication. They share self-created content, post their opinions and link to other content online more than any other demographic groups (Lenhart et al., 2011). They also rely upon SNS as a core component of their social lives (Boyd \& Pennebaker, 2015; Yang \& Brown, 2016) and will typically use SNS to build new peer affiliations, manage existing relationships as well as stay informed about social activities within their network. Given that teenagers are typically concerned with peer acceptance, physical appearance, and self-impressions they convey, they are drawn or attracted to SNS because these sites enable them to connect with their peers without adult surveillance, facilitate identity construction and experimentation within a social context (Livingstone, 2008). Cooper and Dzara (2010) assert that SNS provide teens with the opportunity to explore and reconfigure their gender identities, while simultaneously clarifying to themselves who they are. More recent studies reported that SNS provide an interactive platform in which selfpresentation and peer influences interact to coconstruct the standards of beauty (Meier \& Gray, 2014). Instagram and Facebook have actually assisted how peers compare their look and image among teenagers (Mascheroni et al., 2015).

Studies on how teenagers and emerging adults' present themselves through their SNS profile photographs reported that the two groups used SNS to enhance the users' positive self-presentation to others (Walther \& D'Addario, 2001). Manago et al. (2008) found that female present stereotypically gendered images of attractive women, whereas Kapidzic and Herring (2011) study on teenage girls reported that majority of girls posted profile photographs that present themselves in a seductive manner by dressing in revealing dresses. This is akin to Wegenstein (2012) who opines that that the meanings of beauty are socially constructed as teenage girls are receptive to peer norms of beauty, by emphasizing physical features such as bright eyes, flawless skin, and thinness.

At this point, it is evident that the types of photos posted, particularly the profile photos in SNS are crucial because the photos can make favourable and lasting impression on others, an impression that corresponds to social ideals (Kim \& Dindia, 2011) and relational success (Hancock \& Toma, 2009). People with a profile photo on their Facebook profile page are seven times more often contacted than users whose profile does not contain a photo (Hancock \& Toma 2009). According to Ellison et al. (2007), people use their profile photo to communicate specific aspects of their identity such as their lifestyle or profession. Moreover, people not only pay attention to the photo they choose to display online but also to the specific poses they take (Ellison et al., 2007). As popular forms of social media, correlational research on social networking sites has demonstrated that social networking site use is associated with internalization of beauty ideals, body dissatisfaction and disordered eating (Fardouly \& Vartanian, 2015; Mabe et al., 2014; Meier \& Gray, 2014).

Although studies have been done to compare Facebook self-presentation across ages, majority of past studies focused on teenagers or newly registered college students. Results from past studies (e.g., Cooper \& Dzara, 2010; Kapidzic \& Herring, 2011; Mascheroni et al., 2015) focused on female teenagers' self-presentation on Facebook and female who are in their first year of college. This has raised a question about how older users of Facebook, particularly, emerging adults manage their profile images compared to younger users. Therefore, based on the reviewed past studies (Cooper \& Dzara, 2010; Kapidzic \& Herring, 2011, 2015; Livingstone, 2008; Manago et al., 2008; Mascheroni et al., 2015; Wegenstein, 2012), the present study aims to extend the scope of past studies, which is to examine differences or similarities between teenagers and emerging adults with regards to how they present themselves via photos on Facebook. The study posits that age could be a determining factor. In addition, the past studies about SNS in Malaysia (Balakrishnan \& Azra, 2013; Safurah, et al., 2010; Siew Ming et al., 2013; Yon et al., 2016) clearly established that none of the studies in Malaysia analysed how teenagers and emerging adults presented themselves on Facebook. Hence, the present study aims to investigate how teenagers and emerging adults in the Malaysian context present themselves by analysing the photos they posted on Facebook and to find out the differences and similarities of photos posted by teenagers and emerging adults on Facebook. Two research objectives have been formulated to:

1. analyse visual representations of female teenagers and emerging adults on Facebook;

2. examine differences and similarities between teenagers and emerging adults' visual presentations of themselves on Facebook.

\section{Self-Presentation in Social Networking Site}

The combination of the availability of high-speed internet and the popularity of social networking sites (SNS) represents a shift from anonymity towards 
"nonymity" (Zhao et al., 2008), which refers to online self-presentation. Among the various psychological phenomenon that SNS presents, selfpresentation behavior has been receiving much attention. Goffman (1959) was among the first to acknowledge that individual needs to present themselves to others as a person with desirable image. He described how individuals can be strategic in managing the impressions they give to others. Metaphorically speaking, people would wear masks, play roles, and present themselves in the ways they see themselves or in the ways they desire to be seen by others (Goffman, 1959). Goffman's conceptualization is akin to Leary's (1996) view of concept management, based on the assumption that individuals have an innate need to be accepted and involved, and, therefore, act accordingly (Leary, 1996).

Schlenker (1980) opines that self-presentation is a behavior aimed at conveying an image of self to others. Its primary goal is to influence other people to respond in desired ways (Leary \& Kowalski, 1990). Walther (1996) added that self-presentation is often regarded as a more strategic form of impression management and the projection of online identity. Bolino et al. (2008) sum up that individuals manage their impressions when they wish to present a favourable image of themselves to others. The act of posting photos of oneself on social media is typically intended to enhance the user's positive self-presentation (Walther \& D'Addario, 2001). Walther et al. (2008) also reported that SNS users judge the attractiveness and the personality characteristics of profile owners based on how they present themselves through photographs. Based on the description about self-presentation, the present study adapts Schlenker's (1980) and Walther's (1996) description of self-presentation. Hence, selfpresentation in the current study refers to a behavior which involves conveying an image of self to others (Schlenker, 1980) for impression management and for projecting an online identity (Walther, 1996).

A study on self-presentation in online-dating environment by Ellison et al. (2006) revealed that the photographs used for the profile photos served to warrant or support claims made in textual descriptions. This means that people used photographs not only to visualize their look, but also to emphasize the things and qualities that are important for them. Ellison et al. (2006) also pointed out that a photo of a man posted without a shirt on and another photo of the same man standing in front of a wall where his diploma is displayed functions at different levels. The posted photos provide an overview of a person's self-concept and physical characteristics. Whitty's (2008) study on the onlinedating site users revealed that individual regularly edit the photos posted and descriptions about the photos to find out which photos and descriptions would be more successful at attracting others to their profile because the need to present a good physical image than any other characteristics is of utmost importance (Whitty, 2008). In fact, this is supported by the fact that some online-dating site users have a glamorous-shot to accompany their textual profiles. Mascheroni et al. (2015) illustrated how visual images are building blocks for a person's identity that allows a person to demonstrate the image that he or she chooses to present. The study conducted by Santarossa et al. (2019) on content category analysis of Instagram on 122 images found 'appearance' to be the largest content categories, confirming that images are associated with good feelings and appearance.

\section{Kress and van Leeuwen's metafunctional framework}

Kress and van Leeuween's metafunctional framework $(1996,2006)$ is the most relevant theory employed to analyze the photos posted onn Facebook. Kress and van Leeuwen's metafunctional framework (1996, 2006) consists of representational meaning, interactive meaning, and compositional meaning. Each category is further divided into subcategories, as described in table 1 . Kress and van Leeuwen considered "the visual, like all semiotic modes [as serving] several communicational (and representational) requirements, in order to function as a full system of communication (2006, p. 41). Each category and sub - categories will be used in the analysis to fulfil research objective 1 - to analyse the visual representations displayed by female teenagers and emerging adults on Facebook. The analysis of the visual representations will then enable the researchers to answer objective 2 - to examine the differences and similarities between teenagers and emerging adults' visual presentations of themselves on Facebook. The detailed description of each category and sub - categories is given in Table 1 .

\section{METHOD \\ Respondents}

The present study is based on analysis of visual images which employed Kress and van Leeuwen's metafunctional framework (1996; 2006). The framework consisted of three categories and further sub-categories (see Table 1). The elements (refer to description for each category and sub-categories in Table 1) will be employed to analyse the visual images posted by teenagers and emerging adults on their Facebook. Participants of the present study consisted of 40 females who were selected according to a set of criteria determined by the researchers, including gender, age, geographical location and Facebook access. It is a fact that a Facebook status is set by the Facebook owner. Therefore, the researchers had to ask each participant's consent to be the participant's friends in 
order that the researchers can have access to the participants' Facebook. Only female participants were selected for the study as young female users posted more photos than male counterparts (Pempek et al., 2009). Furthermore, data obtained from https://www.statista.com/statistics/376128/ facebook -global-user-age-distribution/ (Clement, 2020) showed that as of January 2020, ten percent of global active Facebook users were women between the ages of 18 and 24 years. The data about Facebook users in
2019 for male and female users revealed that there were more female users than male users, with $56 \%$ female using Facebook and $44 \%$ male using Facebook (Lambert, 2020, https://financesonline. com/number-of-social-media-users/) The present study adopted Lenhart et al. (2011) to determine the age group for teenagers, i.e., those between the age of 12 to 17. As for female emerging adults, we adopted Arnett's (2000) definition of emerging adults, that is, those between the age of 18 to 25 .

Table 1

Kress and van Leeuwen (1996, 2006) Metafunctional Framework

\begin{tabular}{ll}
\hline Function of Meaning & Visual resources \\
\hline $\begin{array}{l}\text { Representational meaning - } \\
\text { discuss the internal relations between the }\end{array}$ & $\begin{array}{l}\text { Narrative process - narrative process is dynamic and serving to "present } \\
\text { depicted participants. }\end{array}$ \\
& arrangements. Consists of action process and reactional process. \\
& Conceptual process - static process (no vectors) and represent participants in \\
& terms of their "more generalized and more or less stable and timeless \\
& essence, in terms of class, or structure or meaning". Consists of analytical \\
and symbolic processes.
\end{tabular}

\section{Interactive meaning -}

discusses the way images represent relations between people, places, things they depict, and the complex set of relations that exist between images and the perceived audience.

\section{Compositional meaning -}

discusses the way in which the representations and communicative acts cohere into the kind of meaningful whole referred to a "text".
Social distance - influenced by different sizes of frame, namely close-up, medium or long.

- Personal (close-up)

- Social (medium shot)

- Impersonal (long shot)

Image act - image act is related to the gaze direction of the represented participants which can be directed at the viewer; (demand) or not (offer).

- Offer (absence of gaze at viewer)

- $\quad$ Demand (direct gaze)

Subjectivity - implies the possibility of expressing subjective attitudes towards represented participants, depicted from various angles, such as lowangle shot, eye-level shot and high-angle shot.

Information value - how the placement of elements gives specific informational values attached to the various "zones" of the image: left and right (given and new information), top and bottom (ideal and real information), and center and margin (nucleus and subservient information).

Salience - important system in the composition of visuals. Some elements are presented as more important or attractive than others. The visual clues indicating salience are: size, sharpness of focus, tonal contrasts, color contrast, placement in the visual field, perspective and specific cultural factors.

Framing - discusses how the presence or absence of framing devices disconnects or connects elements of the image.
Where geographical location is concerned, the selected participants are residing in urban residences only. This is because Internet access in urban areas is better and the data needed for the present study, which is largely dependent on access to the Internet connection (Arribas-Bel, 2014). Since this study involved data collection from Facebook, the participants had to be active users of Facebook posting more photos, presumably on daily basis. The visual images analysis involved qualitative analysis which involved selection of profile photos posted on the participants' Facebook for a period of one month. Five photos were selected from every participant making up a total of 200 photos. The photos were then analysed by using the metafunction framework (Kress \& van Leeuwen, 1996, 2006), consisting of representational meaning, interactional meaning and compositional meaning categories.

\section{Procedures}

The snowball sampling method was employed, which assisted the researchers in identifying potential subjects, which are hard to locate. This sampling method is chosen for two reasons; (1) the researchers were constrained by time because the research had to be completed within a particular time frame and (2) it is quicker to get respondents because the initial respondent assisted the researchers in getting the next respondent. This process enabled the required number of respondents 
to be obtained within the time frame set for data collection. As stated by Dudovskiy (2016), this sampling method involves primary data sources nominating another potential primary data source to be used in the research. This approach involved the initial subject helping the researcher to identify individual with similar traits of interest. The researcher began with observation of the nominated subject and continued in the same way until sufficient number of subjects were obtained. This sampling method enabled (1) the possibility of collecting primary data in a cost-effective manner, (2) completion of a study in a short duration of time, and (3) little planning is required to start primary data collection process (Dudovskiy, 2016).

A consent form was given to the participating individual due to privacy restrictions policy, which gave permission to the researcher, to only view and analyse the photos on the site after the participant has approved the researcher's request as friend. One of the biggest areas of concern for the researcher with social media data is the extent to whether such data should be considered as public or private data. Key to this argument is the standpoint that social media users have all agreed to a set of terms and conditions for each social media platform that they use, and within these terms and conditions there are often contained clauses on how one's data may be accessed by third parties, including researchers (Boyd \& Crawford, 2012). Then, the researcher specifically stated the items and features on the Facebook page of the participants which will be collected as data, as well as information about the study, along with the consent letter. The letter of consent is in Appendix 1 and 2. After gaining access to the participant's Facebook profile page, the researcher analysed photos selected from the profile photo section on each participants' Facebook profile page.

\section{Data analysis}

The image analysis involved simultaneous analysis of representational, interactional and compositional meaning including the four stages of analysis. In the first stage, the images were obtained based on the specified sample criteria - 1) gender, 2) age, 3) geographical location, and 4) active user of Facebook. In the second stage, the photos were analysed according to how the participant was depicted in the image as to whether or not the participant was represented as performing an action (narrative/conceptualized representation), and whether the images appeared to be digitally edited (visual modality). The researcher further analysed how the images were characterized by their interactive meaning in terms of gaze, various kinds of shots, and angles. In the third stage, the analysis was focused on investigating compositional representational and interactive meanings as projected in the images. The analysis for the compositional meaning was conducted after obtaining the results from the representational meaning and interactive meaning. In the fourth stage, the analysis was focused on identifying the differences and similarities in self-presentation from the photos posted by the female adolescents and youth, with the aim of answering the second research objective based on the metafunctional framework (Kress \& van Leeuwen, 1996; 2016).

\section{FINDINGS}

The result section begins with visual analysis of teenagers and emerging adults based on Kress and van Leeuwen's metafunctional framework (1996; 2006) in order to achieve the first research objective, which is to analyse visual representations of female teenagers and emerging adults on Facebook based on representational meanings (narrative process and conceptual process) and interactive meanings (social distance, image act and subjectivity). Table 2 shows the representational and interactional meanings for teenagers, while Table 3 shows the representational and interactional meanings for emerging adults. After obtaining the results for representational and interactional meanings for both groups, a comparison is made between the two groups.

Table 2

Representational and Interactive Meanings for Teenagers

\begin{tabular}{|c|c|c|c|c|c|c|c|c|}
\hline $\begin{array}{l}\text { Function of } \\
\text { meaning }\end{array}$ & & & & Visua & esources & & & \\
\hline $\begin{array}{l}\text { Representational } \\
\text { meaning }\end{array}$ & $\begin{array}{c}\text { Decon- } \\
\text { textualised } \\
6 \%\end{array}$ & $\begin{array}{c}\text { Con- } \\
\text { textualised } \\
\mathbf{9 4 \%}\end{array}$ & $\begin{array}{c}\text { Edited } \\
\mathbf{7 4 \%}\end{array}$ & $\begin{array}{c}\text { Unedited } \\
26 \%\end{array}$ & $\begin{array}{c}\text { Con- } \\
\text { ceptual } \\
\mathbf{9 4 \%}\end{array}$ & $\begin{array}{c}\text { Narrative } \\
6 \%\end{array}$ & & \\
\hline $\begin{array}{l}\text { Interactional } \\
\text { meaning }\end{array}$ & $\begin{array}{c}\text { Close-up } \\
\mathbf{6 1 \%}\end{array}$ & $\begin{array}{c}\text { Medium } \\
\text { shot } \\
25 \%\end{array}$ & $\begin{array}{c}\text { Long } \\
\text { shot } \\
14 \%\end{array}$ & $\begin{array}{c}\text { Direct gaze } \\
\text { at viewer } \\
\mathbf{6 9 \%}\end{array}$ & $\begin{array}{c}\text { No gaze at } \\
\text { viewer } \\
31 \%\end{array}$ & $\begin{array}{c}\text { Low } \\
\text { angle shot } \\
10 \%\end{array}$ & $\begin{array}{c}\text { Eye-level } \\
\text { shot } \\
\mathbf{8 4 \%}\end{array}$ & $\begin{array}{c}\text { High } \\
\text { angle shot } \\
6 \%\end{array}$ \\
\hline
\end{tabular}

Representational and interactional meanings for teenagers

As indicated in Table 2, the majority of images are contextualized (94\%), edited (74\%) and conceptualized (94\%). A high percentage of contextualized images (94\%) means that there is background image. The contextualised images with the background in the photo provided information to 
the viewers about the location of the photos, the time when the photos were taken (day or night) and whether the photo was captured indoor or outdoor. Where editing is concerned, there is a high percentage of editing (74\%). This means that the photos were edited with regards to contrasts, sharpness and colour saturation. Filters are also used to enhance the participant's photos. Digital stickers such as flower crowns, dog's ears and face tattoos can be obtained by downloading Snapchat, for the purpose of making the photos more attractive. The conceptual process is also high (94\%), which means that teenagers prefer to take photos which portrayed them as active individuals.

For interactional meaning process, the results reveal that teenagers prefer photos which made them appear close to the viewers (close up at 61\%). Many of their photos show that they were looking directly at the viewers (direct gaze at $71 \%$ ) and with the eyelevel shot $(84 \%)$. Direct gaze implies demand and generally causes the viewers to feel strong engagement with the participants, while eye level angle shows equal relation with the viewers.

Table 3

Results for Representational and Interactional Meanings for Emerging Adult

\begin{tabular}{lcccccccc}
\hline $\begin{array}{l}\text { Function of } \\
\text { meaning }\end{array}$ & \multicolumn{7}{c}{ Visual resources } \\
\hline Representational & Decon- & Con- & Edited & Unedited & Conceptual & Narrative \\
meaning & textualised & textualised & $\mathbf{7 0 \%}$ & $30 \%$ & $\mathbf{8 3 \%}$ & $17 \%$ \\
& $2 \%$ & $\mathbf{9 8 \%}$ & & & & & \\
Interactional & Close-up & Medium & Long & Direct gaze & No gaze at & Low angle & Close- & Medium \\
meaning & & shot & shot & at viewer & viewer & shot & up & shot \\
& $22 \%$ & $\mathbf{5 2 \%}$ & $26 \%$ & $\mathbf{5 8 \%}$ & $42 \%$ & $11 \%$ & $22 \%$ & $\mathbf{5 2 \%}$ \\
\hline
\end{tabular}

\section{Representational and interactional meanings for emerging adults}

Results for emerging adults as shown in Table 3 reveal that the majority of images for representational meaning was contextualized at $98 \%$, edited at $70 \%$, and conceptualized at $83 \%$. Emerging adults prefer contextualized images which provided information to their viewers about their location, the setting (indoor or outdoor) and when the photos were taken. The percentage of editing $(70 \%)$ means that the photos were edited, using some forms of photo filters, for instance, the participants' image was more prominent than the background and had some colour saturation. Filters can age a photo, make colors more vibrant, or give photos a cooler color temperature. In fact, some filters overlay masks in the image or add borders or frames (Meehan, 1998, in Bakshi et al., 2015). Results for conceptual process is also high (84\%), which means that emerging adults had the tendency to take photos which portrayed them as active individuals.

Results based on the interactional meaning process show that emerging adults prefer medium shot photos $(52 \%)$, in which only the upper body of the participants (from head to the chest area) was shown in the images. This implies that the participants preferred to remain at a distance from the viewers. However, the percentage of direct gaze at viewers was higher $(52 \%)$ than no gaze at viewers $(42 \%)$. This means that although the participants remained at a distance, they still wanted to have strong engagement with the viewers by looking directly at the viewers. Emerging adults also wanted to show that they had equal relations with the viewers because the percentage of eye level shot (77\%) was much higher than high angle shot (12\%).
Comparison of representational meanings for teenagers and emerging adults

Representational meanings deal with the relations between participants and the narrative and conceptual processes. Table 2 shows that with regards to representational meanings for teenagers, the majority of the images were contextualized (94\%), edited (74\%) and conceptualized (94\%). The result for emerging adults, as shown in table 3 , did not differ much from the teenagers. The majority of images for representational meanings was contextualized at $98 \%$, which was slightly higher than teenagers by $4 \%$, edited images at $70 \%$, which was slightly less than the teenagers by $4 \%$, and conceptualized images at $83 \%$. The percentage of conceptualized images was higher for teenagers than emerging adults by $11 \%$. The results for both groups mean that both teenagers and emerging adults paid a lot of attention to the photos that they posted online.

Comparison of interactional meanings for teenagers and emerging adults

As illustrated in table 2, for interactional meaning, the majority of the images for teenagers was closeup $(61 \%)$, direct gaze $(69 \%)$ and shot at eye-level position (84\%). The result for emerging adults, as shown in table 3, did not differ much from the result for teenagers. The results in table 3 demonstrate that the majority of images was medium shot at $52 \%$, which is lower by $9 \%$ than teenagers, direct gaze ( 58 $\%$ ), which is also lower by $11 \%$ than teenagers, and was shot at eye-level $(77 \%)$. The eye-level images were also lower in percentage than teenagers by $7 \%$. Where conceptual image was concerned, the percentage of conceptualized image for teenagers was $94 \%$ and $83 \%$ for emerging adults. The result for interactional meanings reveals that teenagers 
paid more attention to the photos that they posted online, which suggest that teenagers wanted to be close to their friends or followers of their Facebook.

The next section depicts qualitative analysis based on selected photos of teenagers and emerging adults to answer the first research objective: to examine the visual representations displayed by female teenagers and emerging adults on Facebook. The results from the qualitative analysis provides answers to the second research objective: to examine differences or similarities of visual selfpresentation between teenagers and emerging adults on Facebook. It is pertinent to point out that the analysis focused only on results obtained for high percentage of images (depicted in Table 2 and 3), which are representational (contextualized, edited, conceptual) and interactional meanings (close shot, medium shot, direct gaze and eye level shot). The results for compositional meanings are presented and discussed together with representational and interactive meanings because the analysis for compositional meanings depends on the analysis of the representational and interactive meanings.

\section{Representational and compositional meanings}

Representational meanings comprise narrative and conceptual processes. Compositional meanings, on the other hand, consist of information value, salience, and framing.

\section{Narrative processes between teenagers and emerging adults}

Emerging adults are more mature than teenagers, thus, photos which showed them in narrative images, i.e., involvement in activity was expected to be higher than teenagers. The percentage of narrative images for emerging adults was higher by $17 \%$ than for teenagers (see Table 3). Arnett (2000) points out that emerging adults actively sought a sense of who they are by exploring possibilities, as they are in a critical period for identity development. This explains why there was a higher percentage for emerging adults for narrative images.

For example, the photos in Figure 1 (A and B) showed the participants were actively performing some actions. The teenager probably attended a birthday party based on the images of the balloons. Photo A was probably taken at a photo booth. The emerging adult was photographed caressing a cat. Both photos involved an action between the actors and the goal, hence, the photos depicted some forms of symbolic processes.

The analysis for compositional meanings is based on information value, salience and framing. The information value result reveals that the images of the participants were horizontal because the teenager and the emerging adults were placed in the center of the photos as given/known information. The background was represented as the new information. Where salience was concerned, both participants captured the viewers' attention because their image was sharper and stood in contrast to the background. The viewers were forced to focus on the participants before shifting their attention to the background. As for framing, the photos contained no demarcation with regards to specific lines of frame. This means that the combination of the background and the participants expressed the participants' intention which was to share their activities with the viewers.

\section{Figure 1}

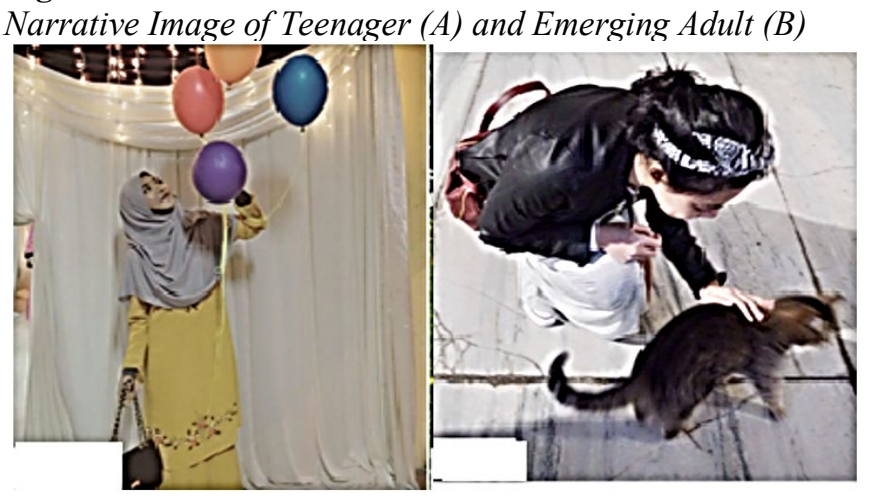

\section{Conceptual process for teenagers and emerging adults}

Conceptual processes involved representation of the participants in terms of their actions or activities in which they were involved. Both groups of images were represented in a passive position, whereby they were merely smiling and looking directly at the camera. Table 2 and 3 demonstrate that the percentage for conceptualized image was higher for teenagers (94\%) than emerging adults (83\%).
Teenagers are usually more concerned about their appearance (Kapidzic \& Herring, 2011; Livingstone, 2008; Manago, 2008; Wegenstein, 2012). As depicted in Figure 2, both participants (A and B) were looking directly at the camera that featured close-up images.

The teenager was most probably indoor because she seemed to be standing against a wall, while the photo of the emerging adult was taken outside, at night. Images of buildings and lights 
could be seen at a slight distance behind the emerging adult. Although the background information was present in the photo, the emerging adult is the focus in the photo. The analysis of the compositional meaning revealed that her image was more salient because it was sharper than and in contrast with the background. Nevertheless, the teenager's photo (A) was more salient compared to the emerging adult (B) because the image in photo A took up almost the entire space. Nevertheless, there was a separation with regards to the lines of frame in the photos because the participants wanted their image to be differentiated from the background.

\section{Figure 2}

Conceptual Image of Teenager (A) and Emerging Adult (B)

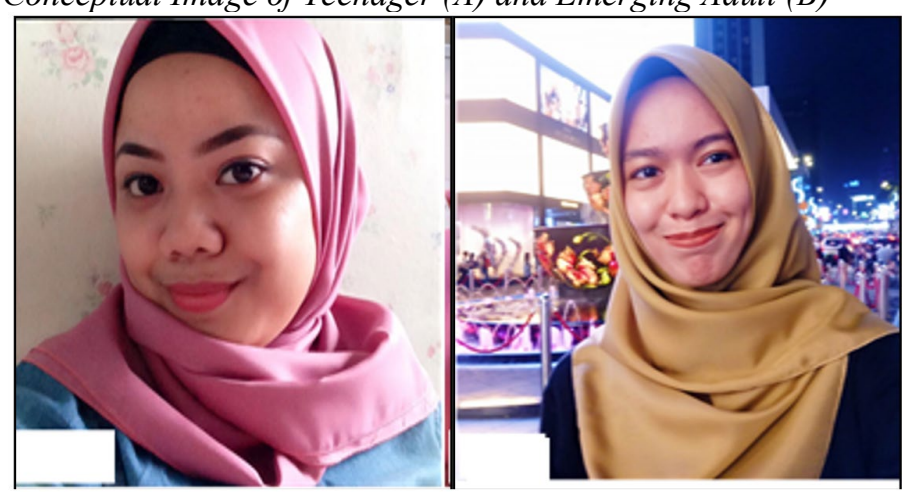

\section{DISCUSSION}

The results of the visual analysis of photos in both groups affirm that teenagers and emerging adults used SNS to enhance the users' positive selfpresentation to others (Walther \& D'Addario, 2001). Both groups posted photos which appeared to be edited to make them appear more presentable and attractive. The result is in line with the findings of Manago et al. (2008), who found that subjects in their study edited the photos using image editing tools and applications in order to present the most attractive photos. Several photos in the present study were edited by using the Snapchat application in which images of flowers and other objects were added to the photos. This finding is also akin to Siibak's (2009) study indicating that girls emphasized the importance of photo editing. Similarly, Huang (2014) indicated that adolescents used social media to share photos that made them look good to get good compliments from friends, while Santarossa et al. (2019) found 'appearance' was the largest content categories in SNS, which confirms that images are associated with good feelings and appearance. Meier and Gray (2014) also asserted that SNS provided an interactive platform in which self-presentation and peer influences interacted to co-construct the standards of beauty.

Kapidzic and Herring (2011), and Kapidzic and Herring (2015) found that the teenagers in their study presented themselves in a sexualized way, for example in revealing clothing and flirtatious gaze. However, the result in the present study differs. Both teenagers and emerging adults did not dress in any revealing clothes or posed flirtatiously. Since the current study was conducted in the Malaysian context, the difference is attributed to culture and religion. The participants live in a society where wearing revealing clothes in public is associated with immoral behaviour. In addition, almost all of the participants in the current study wore hijab. Wearing hijab comes with decent clothing. In the past, garments that were not directly connected to the Western fashion system tended to be labelled as "ethnic dress" or even "folk costume" (Baizerman, et. al. 1993, in Khalid, 2020). However, Jones and Leshkowich (2003, p. 19, in Khalid, 2020) observed that "During the 1990s, Asian fashion became a noticeable global trend", which was not strictly "Chinese" or "Japanese" but combined elements from different Asian cultures. This means that the Asian culture dressing or images are a culture acknowledged by the West.

The visual analysis reveals that most images of particularly from the teenagers, are at eye level shot implying that the participants are expressing equal relations with the viewers (Kress \& van Leeuwen, 1996; 2006). This supports Ellison's et al. (2007) view acruing that people not only pay attention to the photo they choose to display online but also to the specific poses they take. The eye level shot pose not only expresses equal relations, but according to Subrahmanyam et al. (2004), the pose indicates that the person is warm and open to others. This trait is considered a necessity for attracting more acquaintances (Subrahmanyam et al., 2004).

Both age groups prefer to be seen as active individuals by engaging in some kinds of acts. However, there are more images of emerging adults getting involved in indoor or outdoor activities. The narrative image structure aligns with emerging adults who want to portray their identities as active 
youth, hence, resulting in their involvement in indoor and outdoor activities. They also want to keep their social network informed of their social activities (Boyd \& Pennebaker, 2015; Yang \& Brown, 2016). Photos of the emerging adults show that they are mostly outdoor (Figure 1 - the teenager and the emerging adult are outside and are performing some kind of action, Figure 2 - shot outside at night). The combination of the narrative image, salience and framing (Kress \& van Leeuwen, 2006) is related to convey one idea, which is active and inquisitive.

Teenagers have more close-up shot images compared to emerging adults because they want to appear more intimate and closer with their viewers. Kapidzic and Herring (2015) reported that female teens posted significantly more images at closer distances to convey their level of intimacy to their perceived audience. Chua and Chang (2016) found that this pose implies that the teenagers endeavor to seek peer recognition and present a better self-image online. Teenagers tend to seek popularity by having many friends, hence, the close-up shot images as opined by Subrahmanyam et al. (2004) are necessary for attracting more acquaintances. In addition, the results also reveal that the majority of teenagers presented demanding images in which the person gazed directly at the viewers. On the other hand, emerging adults have higher percentage of photos in which the participants avert their gaze. This implies that emerging adults do not want to be seen as seeking either a dominant or a friendly relationship with the perceived audience. Kapidzic and Herring (2015) pointed out that emerging adults used SNS to maintain friendship, rather than looking for new ones.

The results of the present study reveal the importance of understanding teenagers and emerging adults' online self-presentation which can help increase understanding about how this age group perceives themselves on SNS, since the results have affirmed that SNS allows users to have greater control over their self-presentation as users create personal profiles, control what images and/or posts they share to represent themselves. This supports Harter (2012) who argues that people should be aware of the possibilities of youth using social networking site as an escape from self-esteem struggles and other emotional factors. Apart from that, educating the teenagers and emerging adults is of importance because inexperienced female emerging adults and teenagers, especially, will understand better the undesirable consequences of their online photos that may lead to unwanted attention or intentions from the viewers. This calls for teenage girls, in particular, to be educated about social media literacy in order to understand the meanings put forth on social media, from selfpresentation to feedback about their photos (Chua \& Chang, 2016; Santarossa et al., 2019).

\section{CONCLUSION}

The present research contributes to the extant literature about female teenagers and emerging adults' self-presentation on Facebook by addressing the gap in the Malaysian context about how the two groups present themselves and extend the scope of SNS, and whether age plays a role. The similarities and differences shown in terms of visual presentations between both age groups in the present study confirm that age is one of the factors that influence different interpersonal dynamics of selfpresentation on SNS. This means that different age group conveys different identities to their viewers. Since teenagers appear to pose in images which seek attention and closer relationships with their viewers, via close-up shot images and direct gaze, this suggests that teenagers seek peer recognition and present a friendly self-image online. The study suggests that social media literacy can be introduced to teenage girls to raise their awareness about the meanings on how they present themselves online. In addition, teenagers need to be educated by providing them guidance for online behaviors of selfpresentation.

As mentioned above, this study has contributed to an area that has not been investigated in the Malaysian context, that is how teenagers and emerging adults in Malaysia present their photos on Facebook. Although both groups exhibit behaviors which can be considered universal based on the visual analysis of their online photos, such as selection of photos which has made them appear more presentable, attractive and friendly, an important contribution of this study is how culture and religion play a role with regards to the types of photos and poses posted on SNS. Therefore, this study recommends that future research should consider culture and religion as variables in studies about self-presentation on SNS. Another future suggestion is about the place where the participants reside. The present study only focused on female teenagers and emerging adults living in urban areas in Malaysia. It is recommended that future research include participants from rural areas as they are likely to have different interpersonal behaviors.

\section{ACKNOWLEDGEMENTS}

This paper is based on an MA thesis. The research is one of the studies conducted under the Digital Humanities research group at the Center for Research in Language and Linguistics, Faculty of Social Sciences and Humanities, Universiti Kebangsaan Malaysia. The research group is under the Applied Linguistics cluster. 


\section{REFERENCES}

Arnett, J. J. (2000). Emerging adulthood: A theory of development from the late teens through the twenties. American Psychologist, 55(5), 469480. https://doi.org/10.1037/0003066X.55.5.469

Arribas-Bel, D. (2014). Accidental, open and everywhere: Emerging data sources for theunderstanding of cities. Applied Geography, 49, 45-53.https://doi.org/10.1037/0003066X.55.5.469

Bakhshi, S., Shamma, D. A., Kennedy, L., \& Gilbert, E. (2015). Why we filter our photos and how it impacts engagement [Paper presentation]. Ninth International AAAI Conference on Web and Social Media. https://ojs.aaai.org/index.php/ICWSM/issue/vi ew/273

Balakrishnan, V. \& Azra, S. (2013). Malaysian Facebookers: Motives and addictive behaviours unraveled. Computers in Human Behavior, 29(4), 1342-1349. https://doi.org/10.1016/j.chb.2013.01.010

Bolino, M. C., Kacmar, K. M., Turnley, W. H., \& Gilstrap, J. B. (2008). A multi-level review of impression management motives and behaviors. Journal of Management, 34(6), 1080-1109. https://doi.org/10.1177/0149206308324325

Boyd, D., \& Crawford, K. (2012). Critical questions for big data: Provocations for a cultural, technological, and scholarly phenomenon. Information, Communication \& Society, 15(5), 662-679. https://doi.org/10.1080/1369118x.2012.678878

Boyd, R. L., \& Pennebaker, J. W. (2015). A way with words: Using language for psychological science in the modern era. Consumer Psychology in A Social Media World, 222-236. https:/www.researchgate.net/profile/Ryan_Bo yd2/publication/282651454_A_Way_with_Wo rds_Using_Language_for_Psychological_Scie nce in the Modern_Era/links/56a7073508 ed $2 \overline{2} \mathrm{e} \overline{5} 63 \overline{8} \mathrm{~d} . \mathrm{pdf}$

Chua, T. H. H., \& Chang, L. (2016). Follow me and like my beautiful selfies: Singapore teenage girls' engagement in self-presentation and peer comparison on social media. Computers in Human Behavior, 55, 190-197. https://doi.org/10.1016/j.chb.2015.09.011

Clement, J. (2020). Global social networks ranked by number of users. Statista. https://www.statista.com/statistics/272014/glob al-social-networks-ranked-by-number-of-users/

Cooper, M., \& Dzara, K. (2010) The Facebook revolution: LGBT identity and activism. In M. Cooper \& C. Pullen (Eds), LGBT identity and online new media (pp. 100-112). Routledge.
Dudovskiy, J. (2016). The ultimate guide to writing a dissertation in business studies: A stepbystep assistance. Pittsburgh.

Ellison, N. B., Steinfield, C., \& Lampe, C. (2007). The benefits of Facebook "Friends:" Social capital and college students' use of online social network sites. Journal of Computer Mediated Communication, 12(4), 1143-1168 https://doi.org/10.1111/j.10836101.2007.00367.x.

Ellison, N., Heino, R., \& Gibbs, J. (2006). Managing impressions online: Selfpresentation processes in the online dating environment. Journal of Computer-Mediated Communication, 11(2), 415-441. https://doi.org/10.1111/j.10836101.2006.00020.x

Fardouly, J., \& Vartanian, L. R. (2015). Negative comparisons about one's appearance mediate the relationship between Facebook usage and body image concerns. Body Image, 12, 82-88. https://doi.org/10.1016/j.bodyim.2014.10.004

Goffman, E. (1959). The presentation of self in everyday life. Penguin.

Hancock, J. T., \& Toma, C. L. (2009). Putting your best face forward: The accuracy of online dating photographs. Journal of Communication, 59(2), 367-386. https://doi.org/10.1111/j.14602466.2009.01420.x

Harter, S. (2012). The construction of the self: Developmental and sociocultural foundations (2nd ed.). The Guilford Press.

Huang, H. (2014). Self-presentation tactics in social media. In M. Wang (Ed), Proceedings of the 2014 International Conference on Social Science (pp. 416-421). Atlantis Press.

Kapidzic, S., \& Herring, S. C. (2011). Gender, communication, and self-presentation in teen chatrooms revisited: Have patterns changed? Journal of Computer-Mediated Communication, 17(1), 39-59. https://doi.org/10.1111/j.10836101.2011.01561.x

Kapidzic, S., \& Herring, S. C. (2015). Race, gender, and self-presentation in teen profile photographs. New Media \& Society, 17(6), 958-976. https://doi.org/10.1177/1461444813520301

Khalid, A. (2020). Muslim clothes in fashion world. Pakistan Journal of Art and Culture, 3(3), 1826. http://pjac.com.pk/index.php/PJAC/article/vie $\mathrm{w} / 158$

Kim, J., \& Dindia, K. (2011). Online self-disclosure: A Review of research. In K. B. Wright \& L. M. Webb (Eds), Computer-mediated communication in personal relationships (pp. 156-180). Peter Lang Publishing. 
Kress, G. R, \& Van Leeuwen, T. (2006). Visual interaction. In A. Jaworski \& N Coupland (Eds), The discourse reader (p. 2). Routledge.

Kress, G. R., \& Van Leeuwen, T. (1996). Reading images: The grammar of visual design. Pychology press.

Lambert, S. (2020). Number of social media users in 2020: Demographic \& predications. https://financesonline.com/number-of-socialmedia-users/

Leary, M. R. (1996). Self-presentation: Impression management and interpersonal behaviour. Westview Press.

Leary, M. R., \& Kowalski, R. M. (1990). Impression management: A literature review and two-component model. Psychological Bulletin, 107(1), 34-47. https://doi.org/10.1037/0033-2909.107.1.34

Lenhart, A., Madden, M., Smith, A., Purcell, K., Zickuhr, K., \& Rainie, L. (2011). Teens, kindness and cruelty on social network sites: How American teens navigate the new world of" digital citizenship". Pew Internet \& American Life Project. https://eric.ed.gov/?id=ED537516

Livingstone, S. (2008). Taking risky opportunities in youthful content creation: Teenagers' use of social networking sites for intimacy, privacy and self-expression. New Media \& Society, 10(3), 393-411. https://doi.org/10.1177/1461444808089415

Mabe, A. G., Forney, K. J., \& Keel, P. K. (2014). Do you 'like' my photo? Facebook use maintains eating disorder risk. International Journal of Eating Disorders, 47(5), 516-523. https://doi.org/10.1002/eat.22254

Manago, A. M., Graham, M. B., Greenfield, P. M., \& Salimkhan, G. (2008). Self-presentation and gender on Myspace. Journal of Applied Developmental Psychology, 29(6), 446-458. https://doi.org/10.1016/j.appdev.2008.07.001

Mascheroni, G., Vincent, J., \& Jimenez, E. (2015). "Girls are addicted to likes so they postseminaked selfies": Peer mediation, normativity and the construction of identity online. Cyberpsychology: Journal of Psychosocial Research on Cyberspace, 9(1), 1-14. https://doi.org/10.5817/cp2015-1-5

Meier, E. P., \& Gray. J. (2014). Facebook photo activity associated with body image disturbance in adolescent girls. Cyberpsychology, Behavior, and Social Networking, 17(4), 199-206. https://doi.org/10.1089/cyber.2013.0305

Neira, C. J., \& Barber, B. L. (2014). Social networking site use: Linked to adolescents' social self-concept, self-esteem, and depressed mood. Australian Journal of Psychology, 66(1), 56-64. https://doi.org/10.1111/ajpy.12034
Pempek, T. A., Yermolayeva, Y. A., \& Calvert, S. L. (2009). College students' social networking experiences on Facebook. Journal of Applied Developmental Psychology, 30(3), 227-238. https://doi.org/10.1016/j.appdev.2008.12.010

Prenksy, M. (2001). Digital natives, digital immigrants: Part 1. On the Horizon, 9(5), 1-6. https://doi.org/10.1108/10748120110424816

Safurah, A. J., Khaizuran, A. J., \& Azmi, A. L. (2013). Social media and our youths today: Exploring the impact of social media on Malaysian youths. igi.global.com. https://doi.org/10.4018/978-1-4666-28519.ch012

Santarossa, S., Coyne, P., Lisinski, C., \& Woodruff, Sarah, J. (2019). \#fitspo on Instagram: A mixed-methods approach using Netlytic and photo analysis, uncovering the online discussion and author/image characteristics. Journal of Health Psychology, 24(3), 376-385. https://doi.org/10.1177/1359105316676334

Schlenker, B.R. (1980). Impression management: The self-concept, social identity and interpersonal relations. Brooks/Cole.

Siew Ming, T., Noor, N. M., Shi, N. L., Taha, A. M., \& Aziz, N. B. A. (2017). Influence of social networking on Malaysian female secondary students: A qualitative study across three schools. Akademika, 87(1), 267-278. http://doi.org/10.17576/akad-2017-8701-20

Siibak, A. (2009). Constructing the self through the photo selection-visual impression management on social networking websites.

Cyberpsychology: Journal of Psychosocial Research on Cyberspace, 3(1). https://cyberpsychology.eu/article/view/4218/3 260

Subrahmanyam, K., Greenfield, P. M., \& Tynes, B. (2004). Constructing sexuality and identity in an online teen chat room. Journal of Applied Developmental Psychology, 25(6), 651-666. https://doi.org/10.1016/j.appdev.2004.09.007

Walther, J. B. (1996). Computer-mediated communication: Impersonal, interpersonal, and hyperpersonal interaction. Communication Research, 23(1), 3-43. https://doi.org/10.1177/009365096023001001

Walther, J. B., \& D'Addario, K. P. (2001). The impacts of emoticons on message interpretation in computer-mediated communication. Social Science Computer Review, 19(3), 324-347. https://doi.org/10.1177/089443930101900307

Walther, J. B., Van Der Heide, B., Kim, S. Y., Westerman, D., \& Tong, S. T. (2008). The role of friends' appearance and behavior on evaluations of individuals on Facebook: Are we known by the company we keep? Human Communication Research, 34(1), 28-49. 
https://doi.org/10.1111/j.1468-

2958.2007.00312.x

Wegenstein, B. (2012). The cosmetic gaze: Body modification and the construction of beauty. MIT Press.

Whitty, M. T. (2008). Revealing the real me, searching for the actual you: Presentations of self on an internet dating site. Computers in Human Behavior, 24(4), 1707-1723. https://doi.org/10.1016/j.chb.2007.07.0022

Yang, C. C., \& Brown, B. B. (2016). Online selfpresentation on Facebook and selfdevelopment during the college transition. Journal of Youth and Adolescence, 45(2), 402416. https://doi.org/10.1007/s10964-015-0385$\mathrm{y}$

Yon, H. Y, Hua, T. K., \& Darus, S. (2016). Online self-presentation and impression management (SPIM) among Malaysian tertiary level students on Facebook. In M. Maros, S. Pillai, S. Darus \& N. M. Noor (Eds.), Evolution in language studies. UKM Press.

Zhao, S., Grasmuck, S., \& Martin, J. (2008). Identity construction on Facebook: Digital empowerment in anchored relationships. Computers in human behavior, 24(5), 18161836.

https://doi.org/10.1016/j.chb.2008.02.012 